\title{
APLIKASI NON DESTRUCTIVE TEST PENETRANT TESTING (NDT-PT) UNTUK ANALISIS HASIL PENGELASAN SMAW 3G BUTT JOINT
}

\author{
Tito Endramawan', Emin Haris ${ }^{2}$, Felix Dionisiuss ${ }^{3}$, Yuliana Prika ${ }^{4}$ \\ 1,2,3,4 Jurusan Teknik Mesin, Politeknik Negeri Indramayu, Indramayu, 45252 \\ $1,2,3,4$ J1. Raya Lohbener Lama no.8 Kec. Lohbener Kab. Indramayu \\ E-mail : titoendramawan@gmail.com ${ }^{1}$, eminharis@gmail.com ${ }^{2}$, dionisiusfelix@gmail.com ${ }^{3}$ \\ yulianaprika@gmail.com ${ }^{4}$
}

\begin{abstract}
Abstrak
Tujuan dari penelitian ini adalah menentukan spesimen uji agar bisa diterima berdasarkan acceptance criteria ASME. Penelitian ini menggunakan material mild steel dengan nilai kekerasan 135 HVN dengan ukuran $30 \mathrm{~cm} \times 20 \mathrm{~cm} \times 1,2 \mathrm{~cm}$ yang disambungkan dengan proses pengelasan SMAW posisi $3 \mathrm{G}$ buttjoint dengan elektroda rooting LB 52U diameter $2.6 \mathrm{~mm}$ menggunakan arus 70 Amper dan tegangan 380 volt, sedangkan untuk filler menggunakan elektroda LB 5218 diameter 3,2 mm dengan arus 80 Amper dan tegangan 380 volt. Pada proses pengelasan banyak hal terjadi yang dipengaruhi oleh banyak faktor baik yang sengaja maupun yang tidak disengaja. Metode untuk menginspeksi hasil lasan salah satunya dengan uji tidak merusak metode dye penetrant (NDT-PT) yang hasilnya akan ditentukan berdasarkan acceptance criteria berdasarkan standar ASME. Hasil pengujian menunjukkan adanya discontinuity berupa adanya porositas pada permukaan hasil pengelasan pada spesimen 1 terdapat rounded terbesar $5 \mathrm{~mm}$ pada jarak $233 \mathrm{~mm}$ sehingga berdasarkan acceptance criteria standar AWS dinyatakan hasil pengelasan tersebut accepted dan pada spesimen 2 terdapat discontinuity pada jarak $233 \mathrm{~mm}$ dengan ukuran $8 \mathrm{~mm}$ sehingga dinyatakan rejected. Hasil rejected ini dapat diperbaiki dengan cara di gouging pada discontinuity tersebut kemudian dilakukan pengelasan.
\end{abstract}

Kata Kunci: NDT-PT, SMAW, Butt Joint, ASME

\begin{abstract}
The purpose of the research are determine acceptance criteria the specimen based on ASME standard. The research used mild steel materials with hardness $220 \mathrm{HVN}$ with sized $30 \mathrm{~cm} \times 20 \mathrm{~cm} \times 1.2 \mathrm{~cm}$ then SMAW welding process position of $3 G$ buttjoint with rooting electrode $L B 52 U$ diameter $2.6 \mathrm{~mm}$ used current 70 Amper and voltage 380 volt, for Filler used LB 5218 electrode $3.2 \mathrm{~mm}$ with current of 80 Amper and voltage of 380 volts. The welding process influenced by many factor which cause failure. The method for inspect result of weld used Non Destructive Test Penetrant Testing (NDT PT) and used ASME standard for acceptance criteria. The test results showed the discontinuity of porosity on the surface of the welded product in specimen 1 is the largest rounded $5 \mathrm{~mm}$ at $233 \mathrm{~mm}$ distance so that based on the acceptance criteria of AWS standard, the welding result is accepted and the specimen 2 there is discontinuity at $233 \mathrm{~mm}$ with the size of $8 \mathrm{~mm}$ so that Otherwise rejected. This rejected result can be improved by gouging the discontinuity and then welded.
\end{abstract}

Keyword: NDT PT, SMAW, Butt Joint, ASME.

\section{PENDAHULUAN}

Kabupaten Indramayu merupakan daerah yang memiliki potensi wisata yang cukup potensial karena kekayaan alam, tradisi, seni dan budaya serta sejarah. Letak Indramayu yang berada di pesisir pantai memiliki berbagai sumber daya alam yang sangat melimpah meliputi hasil laut dengan beraneka ragam jenis ikan. Salah satu sumber daya alam yang melimpah tersebut diantaranya minyak mentah yang dapat diolah untuk menjadi bensin, solar, minyak tanah, dan lain-lain[4].

Adanya industri pengolahan minyak tentu saja membuka banyak lowongan pekerjaan, baik untuk yang bersifat kantoran maupun yang lapangan. Untuk pekerjaan lapangan ini banyak sekali yang dibutuhkan, diantaranya adalah proses pengelsan pipa minyak untuk disalurkan ke daerahdaerah tertentu. Proses pengelasan yang sekarang umumnya dilakukan dengan cara konvensional maupun yang otomatis.

Dibalik keunggulan proses pengelasan yang begitu banyak, akan tetapi dalam proses pengelasan logam hasilnya tidak selalu bagus, hal ini terjadi dipengaruhi oleh banyak faktor baik yang sengaja maupun yang tidak disengaja. Untuk menangani hal tersebut maka diperlukan adanya inspeksi hasil pengelasan agar sesuai dengan keinginan dan aman untuk digunakan. Metode untuk menginspeksi hasil lasan 
salah satunya adalah dengan uji tidak merusak (NDT) metode dye penetrant.

Metode Liquid Penetrant Test (dye penetrant) merupakan metode NDT yang paling sederhana namun mempunyai keunggulan berupa kecepatan dan keakuratan dalam mendeteksi defect yang ada di permukaan. Metode ini digunakan untuk menemukan cacat di permukaan terbuka dari komponen solid, baik logam maupun non logam, seperti keramik dan plastik fiber. Melalui metode ini, cacat pada material akan terlihat lebih jelas dengan melihat indikasi pada permukaan benda uji setelah disemprotkan developer yang kemudian di sket untuk dijadikan pelaporan kerja yang nantinya akan diterjemahkan untuk acceptance criteria.

Pekerjaan untuk uji NDT yang ada di PT Pertamina RU VI Balongan sangat banyak dilakukan dan bersifat rutin yang biasanya digunakan untuk pengecekan/inspeksi pipa aliran minyak dan gas ke daerah lain. Pekerjaan ini pada saat sekarang masih menggunakan tenaga dari luar Indramayu, hal ini dikarenakan belum adanya tenaga kerja asal Indramayu yang bisa melakukan pekerjaan tersebut, padahal pekerjaan tersebut sangat mudah dilakukan oleh masyarakat luas dengan adanya pelatihan-pelatihan untuk uji NDT.

Inspeksi dengan menggunakan metode NDT Penetrant Test ini merupakan pekerjaan yang menjanjikan untuk masyarakat Indramayu karena mempunyai nilai yang tinggi namun dengan cara yang mudah dan waktu cepat. Berdasarkan keterangan yang diperoleh dari pihak subkontraktor untuk pekerjaan NDT Penetrant Test ini rutin dilaksanakan dua kali setiap tahun, sehingga sangat besar peluang kerja untuk bidang inspeksi ini.

Penetrant test ini juga dapat digunakan didunia industri pesawat terbang untuk perawatan rutin dalam pengecekan komponen-komponen pesawat, yang didalamnya mengenai prosedur pengujian, persiapan permukaan dari komponen, pelindungan komponen saat pengujian dan semua yang berkaitan dengan pengerjaan penetrant test [7].

Tujuan dari penelitian ini mengetahui jenis defect yang terjadi pada hasil pengelasan SMAW dan menentukan acceptance criteria hasil pengelasan SMAW berdasarkan standar American Welding Society (AWS).

\section{TINJAUAN PUSTAKA}

\subsection{Las SMAW}

Sambungan las adalah sambungan antara dua atau lebih permukaan logam dengan cara mengaplikasikan pemanasan lokal pada permukaan benda yang disambung. Saat ini banyak part yang sebelumnya dibuat dengan cor atau tempa, difabrikasi dengan menggunakan pengelasan. Sebagian besar komponen mesin yang difabrikasi menggunakan sambungan las, menggunakan teknik pengelasan dengan fusion, dimana dua benda kerja yang disambung dicairkan permukaannya yang akan disambung. Beberapa komponen mesin tertentu sering dapat difabrikasi dengan pengelasan, dengan biaya yang lebih murah dibandingkan dengan pengecoran atau tempa [6].

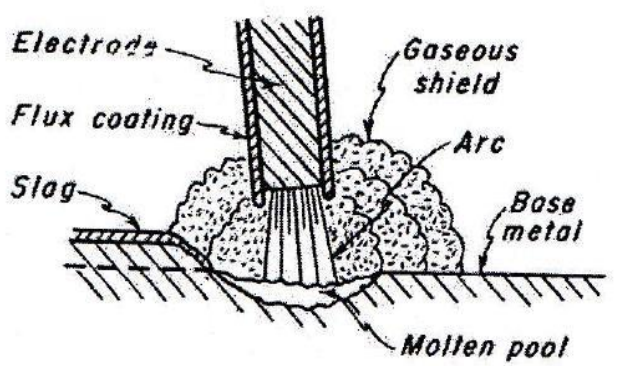

Gambar 1. proses pengelasan SMAW

Kelebihan sambungan las dibandingkan sambungan bautmur atau sambungan keling (rivet) adalah lebih murah untuk pekerjaan dalam jumlah besar, tidak ada kemungkinan sambungan longgar, lebih tahan beban fatigue.

\subsection{Non Destructive Test (NDT)}

Non Destructive Test (NDT) adalah tes fisik suatu material atau benda uji untuk mencari cacat pada benda dengan tidak merusak atau menghancurkan benda uji tersebut. Tujuan dari pengujian NDT adalah untuk mendeteksi cacat dengan suatu psosedur tertentu pada suatu benda oleh seorang operator. Hasil dari pengujian ini akan menentukan suatu part akan diganti atau tidak tergantung dari jumlah cacat yang ada yang merujuk pada suatu standar.

Non destructive Test (NDT) mempunyai banyak metode untuk proses pengujiannya, dan diantara metode tersebut tidak ada yang paling bagus karena dari sekian banyak metode tersebut mempunyai keunggulan masing-masing yang tidak dimiliki oleh metode yang lainnya. Berikut ini beberapa metode yang paling banyak digunakan, diantaranya adalah:

Uji NDT dengan metode visual inspection

Uji NDT dengan metode liquid penetrant

Uji NDT dengan metode magnetik partikel

Uji NDT dengan metode ultrasonic

Uji NDT dengan metode Eddy Current

Uji NDT dengan metode Radigraphy

Berdasarkan tipe keberadaan crack pada material NDT dapat dibedakan dalam 2 macam, yaitu: inside crack dan surface crack. Untuk inside crack ada beberapa metode yang dapat digunakan, seperti radigraphy dan ultrasonic. Sedangkan untuk surface crack dapat dilakukan dengan menggunakan metode visual, liquid penetrant, magnetik partikel, dan eddy current [2].

\subsection{Pengujian Dye Penetrant}

Metode Liquid Penetrant Test merupakan metode NDT yang paling sederhana. Metode ini digunakan untuk menemukan cacat di permukaan terbuka dari komponen solid, baik logam maupun non logam, seperti keramik dan plastik fiber. Melalui metode ini, cacat pada material akan terlihat lebih jelas.

\section{Prinsip pengujian penetrant test}

Metode ini dilakukan dengan beberapa tahap pengujian, yaitu:

a. Membersihkan permukaan benda yang akan diuji. Proses pemberihan ini berguna untuk menghilangkan 
kotoran, debu serta lemak yang menempel pada permukaan benda sehingga cacat pada permukaan tidak tertutup oleh kotoran. Pembersihan ini dilakukan dengan menyemprotkan cleaner penetrant pada permukaan benda kemudian dibersihkan dengan kain sampai permukaan benda benar-benar bersih.

b. Setelah permukaan benda bersih, kemudian permukaan disemprot dengan liquid penetrant sampai rata pada permukaan, lalu dibiarkan selama 10 menit (dwell time). Tujuan dari dwell time ini adalah memberikan kesempatan pada penetrant untuk masuk pada permukaan yang cacat. Penetrant yang digunakan harus mempunyai gaya kapilaritas yang baik agar penetrant dapat masuk pada permukaan yang cacat. Penetrant ini harus mempunyai warna yang terang agar dapat terlihat dengan jelas ketika terjadi cacat pada permukaan ketika disemprotkan developer. Umumnya penetrant menggunakan warna merah dan hijau.

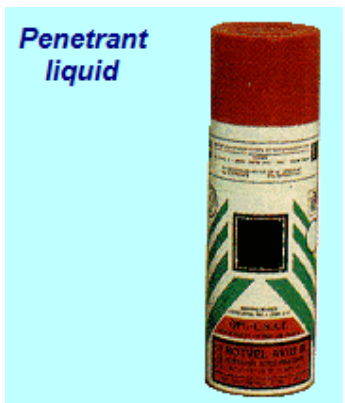

Gambar 2. Penetrant liquid [5]

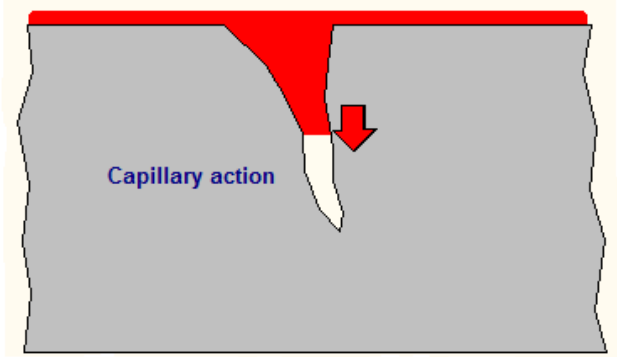

Gambar 3. Proses kapilaritas penetrant [5]

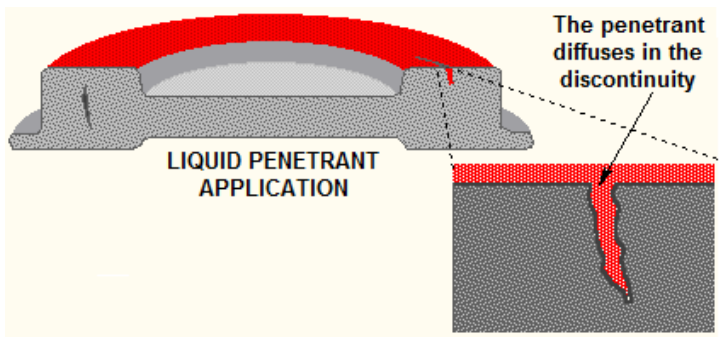

Gambar 4. Liquid penetrant pada cacat [5]

c. Setelah 10 menit, permukaan benda dibersihkan dengan menggunakan kain yang telah dibasahi dengan cleaner penetrant dan dibersihkan dengan arah yang sama.

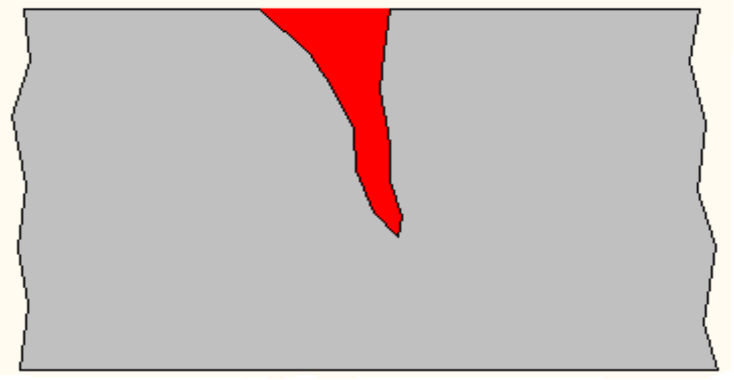

Gambar 5. Penetrant pada permukaan cacat [5]

d. Semprotkan developer penetrant yang sebelumnya telah dikocok pada permukaan benda dengan rata, tunggu beberapa menit, kalau pada permukaan benda terdapat cacat maka akan timbul bercak-bercak cairan penetrant pada permukaan benda. Sifat dari developer ini adalah untuk menarik kembali penetrant yang tertinggal dalam lubang cacat yang dijadikan sebagai tanda terdapatnya cacat pada benda.

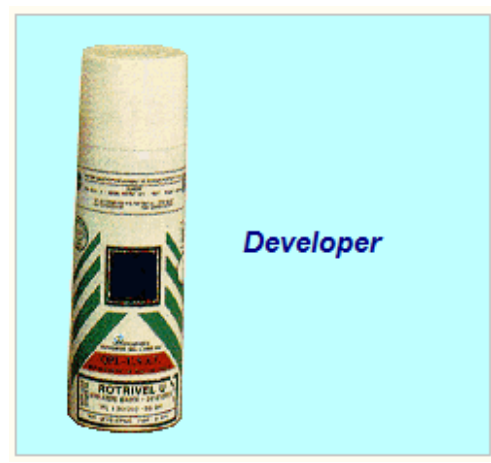

Gambar 6. Developer Penetrant [5]

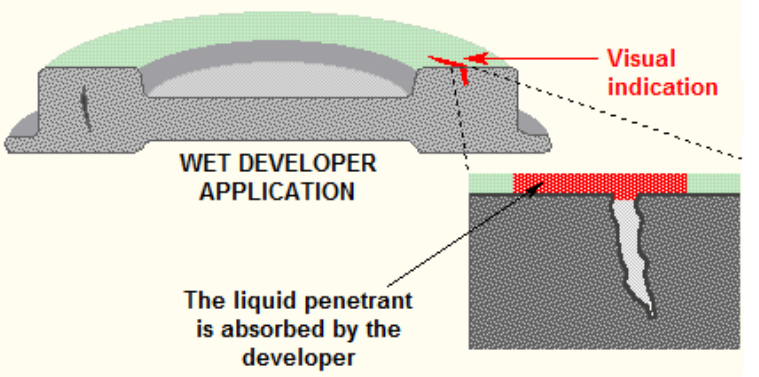

Gambar 7. Pendeteksian cacat permukaan [5]

e. Tandai bagian benda yang terdapat cacat lalu permukaan dibersihkan dengan menyemprotkan cleaner penetrant dan dilap menggunakan kain sampai bersih.

\subsection{Standar AWS dan ASME}

Standar American Society of Mechanical Engineers (ASME) Bagian IX dan American Welding Society (AWS) D1.1 merupakan standar yang paling umum digunakan untuk kualifikasi welder. Komite dan subkomite yang terdiri pekerja relawan tertarik dalam memajukan kualitas dan efisiensi kerja industri pengelasan dengan mengembangkan kode ini. Perbedaan antara ASME Section IX dan AWS D1.1 adalah menamakan fabrikasi, ereksi, inspeksi, dan prosedur pengelasan dan kualifikasi welder. 
ASME adalah khusus untuk kualifikasi tukang las dan las prosedur. Suatu "standar konstruksi" seperti ASME bagian VIII Divisi I harus digunakan bersama dengan Bagian IX untuk fabrikasi. [3]

Beberapa kontrak kerja mengharuskan standar tertentu digunakan untuk kualifikasi welder. Jika pekerjaan terdiri dari konstruksi pengelasan dan kontrak menentukan standar konstruksi AWS, maka standar AWS harus digunakan untuk semua aspek dari pekerjaan. [1]

\section{METODE PENELITIAN}

Pada penelitian ini menggunakan material dari mild steel yang kemudian dilakukan proses pengelasan SMAW posisi $3 \mathrm{G}$ butt joint pada material plat dengan ukuran $30 \mathrm{~cm}$ x 20 $\mathrm{cm} \times 1.2 \mathrm{~cm}$ yang dibevel $30^{\circ}$ pada masing-masing spesimen. Proses pengelasan menggunakan mesin miller maxstar 200 dengan elektroda rooting LB 52U diameter 2.6 mm menggunakan arus 70 Amper dan tegangan 380 volt, sedangkan untuk filler menggunakan elektroda LB 5218 diameter 3,2 $\mathrm{mm}$ dengan arus 80 Amper dan tegangan 380 volt.

Proses uji kekerasan dengan menggunakan mesin innova test tipe verzus 700AS metode vickers dengan penggunaan beban $20 \mathrm{Kgf}$ dan waktu indentasi 10 detik. Metoda uji kekerasan menurut ASTM E-384 menetapkan indentor intan dengan sudut antara permukaan yang saling berhadapan adalah $136^{\circ}$.

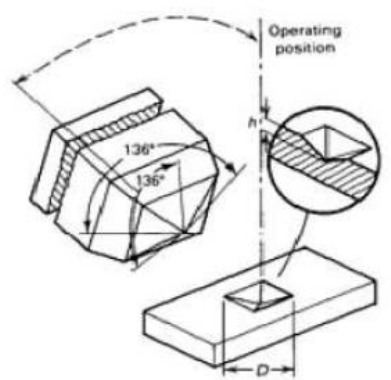

Gambar 8. Pengujian kekerasan Vickers (ASM Metals Handbook, 2000)

Setelah gaya dihilangkan kemudian diukur diagonalnya, sehingga kekerasan vickers dapat dirumuskan dengan persamaan:

$$
H V=\frac{1.8544 P}{d^{2}}
$$

Dengan, $\mathrm{P}=$ beban $(\mathrm{kg})$

$\mathrm{d}=$ diagonal rata-rata $(\mathrm{mm})$

Pengujian NDT metode dye penetrant spotcheck menggunakan merk dagang Magnaflux tipe visible dengan cleaner kode SKC-S No. 170404, Penetrant SKL-SP2 No. 160408 dan developer SKD-S2 No. 170401. Alat bantu yang digunakan antara lain sikat kawat, koas, dan kain lap.

\section{Non Destructive Test Dye Penetrant}

Proses pengujian dye penetrant ini dilakukan dengan tahapan sebagai berikut:

1. Cek intensitas cahaya minimal 1000 lux
2. Cek sensitifitas penetrant menggunakan standar blok

3. Bersihkan permukaan dengan menggunakan sikat kawat untuk membuang kotoran yang menutupi defect

4. Bersihkan permukaan dengan menggunakan solvent untuk menghilangkan kotoran berupa debu, oli dan lainnya

5. Semprotkan penetrant ke permukaan hingga merata

6. Biarkan penetrant (dwell time) selama 10 menit

7. Buang kelebihan penetrant menggunakan solvent pada kain dengan satu arah

8. Keringkan permukaan setelah penggunaan solvent

9. Semprotkan developer ke permukaan secara merata

10. Tunggu developer bereaksi (dwell time) sekitar 30 menit

11. Evaluasi indikasi discontinuity

12. Rekam indikasi discontinuity (indikasi panjang, diameter, letak discontinuity dari titik acuan)

13. Post cleaning dengan menggunakan solvent sampai bersih.

\section{HASIL DAN PEMBAHASAN}

\section{Kekerasan}

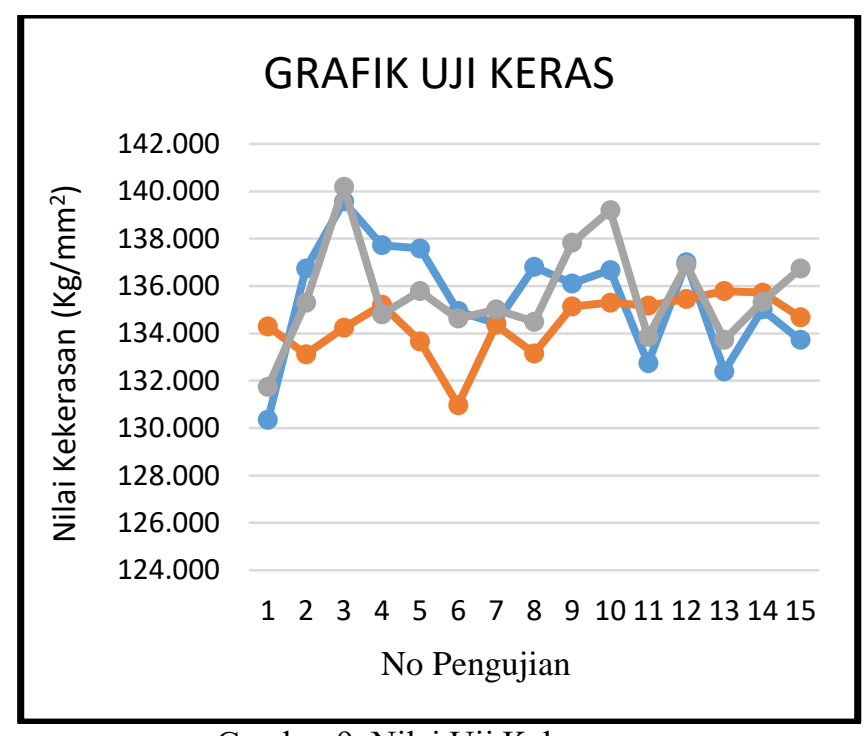

Gambar 9. Nilai Uji Kekerasan

Berdasarkan gambar 9 diatas menunjukkan bahwa kekerasan rata-rata dari base material mild steel adalah 135 VHN dengan nilai kekersan minimum sebesar 131 VHN dan kekerasan maksimum 140 VHN.

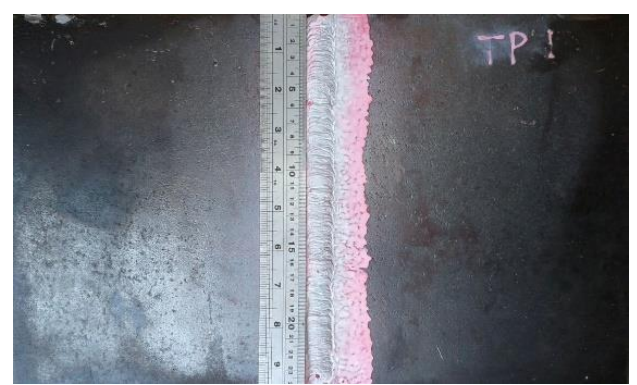

Gambar 10. Spesimen Uji 1 
Tabel 1. Indikasi discontinuity spesimen 1

\begin{tabular}{|c|c|c|c|c|}
\hline No & $\begin{array}{c}\text { Ukuran } \\
(\mathrm{mm})\end{array}$ & $\begin{array}{c}\text { Jarak } \\
(\mathrm{mm})\end{array}$ & Indikasi & Ket. \\
\hline 1 & 3 & 55 & porosity & Accepted \\
\hline 2 & 2 & 164 & porosity & Accepted \\
\hline 3 & 5 & 233 & porosity & Accepted \\
\hline
\end{tabular}

Berdasarkan tabel 1 di atas, menurut standar ASME Section VIII Division 4 mandatory appendix 8 tentang metode pengujian liquid penetrant menyatakan bahwa kriteria standar untuk discontinuity yang terdapat pada hasil pengelasan harus bebas dari linear indication, rounded indication yang lebih besar dari $5 \mathrm{~mm}$ dan terdapat 4 atau lebih rounded indication dengan jarak $1.5 \mathrm{~mm}$. Maka berdasarkan data yang ada maka pada spesimen 1 ini indikasi yang ada masih masuk dalam batasan dari standar yang ada sehingga dinyatakan Accepted.
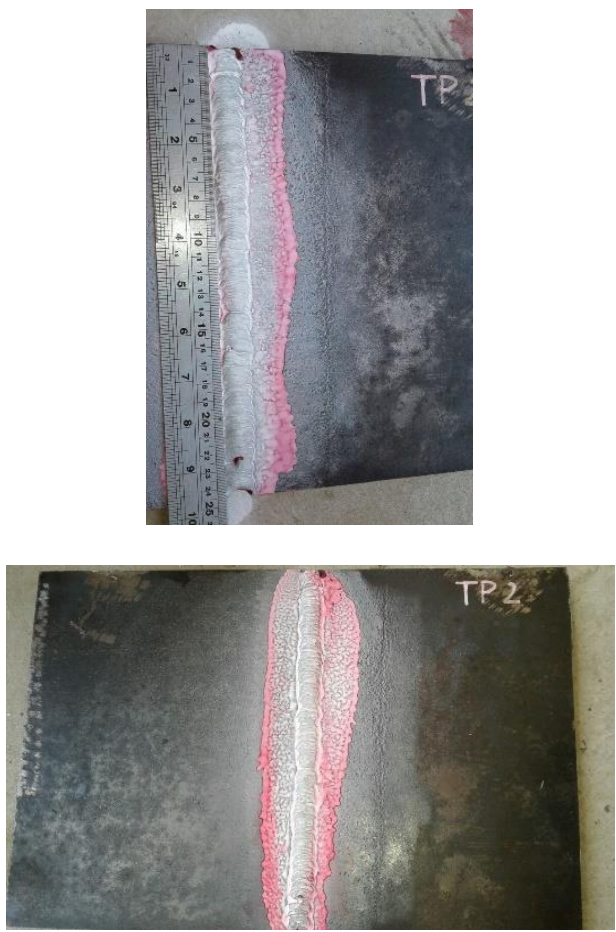

Gambar 11. Spesimen Uji 2

Tabel 2. Indikasi discontinuity spesimen 2

\begin{tabular}{|c|c|c|c|c|}
\hline No & $\begin{array}{c}\text { Ukuran } \\
(\mathrm{mm})\end{array}$ & $\begin{array}{c}\text { Jarak } \\
(\mathrm{mm})\end{array}$ & Indikasi & Ket. \\
\hline 1 & 2 & 162 & porosity & Accepted \\
\hline 2 & 8 & 223 & porosity & Rejected \\
\hline
\end{tabular}

Berdasarkan tabel 1 diatas, menurut standar ASME Section VIII Division 4 mandatory appendix 8, maka berdasarkan data yang ada maka pada spesimen 2 ini indikasi yang ada terdapat indikasi diluar batasan dari standar yang ada sehingga dinyatakan Rejected.

\section{KESIMPULAN}

Berdasarkan data yang telah didapatkan, maka terdapat beberapa kesimpulan diantaranya adalah:

1. Nilai kekerasan dari base material pengelasan rata-rata $220 \mathrm{VHN}$

2. Setelah dilakukan proses pengujian dengan menggunakan NDT PT diketahui terdapat discontinuity pada hasil pengelasan berupa porositas pada permukaan hasil pengelasan. Pada spesimen 1 terdapat beberapa porositas tetapi masih masih dalam batasan acceptance criteria sehingga dinyatakan accepted sedangkan pada spesimen 2 terdapat porositas yang ukurannya diluar batasan yang ada sehingga rejected.

\section{UCAPAN TERIMA KASIH}

Ucapan terimakasih kami haturkan kepada lembaga penelitian dan pengabdian pada masyarakat Politeknik Negeri Indramayu dengan adanya pendanaan dana hibah pengabdian internal tahun anggaran 2017.

\section{DAFTAR PUSTAKA}

[1] American Welding Society (AWS) D1 Committee, "Structural Welding Code - Steel", American National Standards Institute (2010).

[2] Anonim, "Modul Pelatihan NDT Level I dan II", Balai Besar bahan dan Barang Teknik (B4T), 2014.

[3] ASME Boiler and Pressure Vessel Committee, "ASME Boiler and Pressure Vessel Code Section VIII Division I", New York (2013).

[4] http://diskanla.indramayukab.go.id

[5] http://Simula.com/ndtpt

[6] Imam Maolana dan Agus Sifa, "Modul Elemen Mesin I" Politeknik Indramayu, 2012.

[7] Xu Guirong, Guan Xuesong, Qiao Yuliang, GaoYan, "Analysis and Innovation for Penetrant Testing for Airplane Parts" Procedia Engineering 99 (2015) $1438-1442$ 